RAJETÓRIAS

E PERSPECTIVAS 


\title{
Antropologia, Educação e Ética: Desafios no e do Campo Científico
}

\section{Anthropology, Education and Ethics: Challenges in the Scientific Field}

\author{
Neusa Maria Mendes de Gusmão \\ Universidade Estadual de Campinas, Campinas, São Paulo, Brasil
}

\section{RESUMO}

A releitura de dois dossiês com a temática antropologia da/e educação ${ }^{1}$ busca demonstrar os caminhos trilhados por antropólogos e pesquisadores em educação quando adotam a etnografia no âmbito de suas pesquisas. Em tela, um campo científico em construção: a antropologia da/e educação. O texto expõe as alternativas presentes no fazer etnográfico de pesquisadores que atuam na relação entre esses dois campos científicos. Considerase que as escolhas teóricas possibilitam uma diversidade de resultados porque são dependentes dos princípios e das ferramentas adotadas no fazer científico de cada campo. Quais são tais princípios e ferramentas? Quais suas possibilidades e quais seus limites?

Palavras-chave: Antropologia, Educação, Etnografia, Ética, Campo Científico.

\section{ABSTRACT}

The rereading of two dossiers with the theme anthropology of/and education aims to demonstrate the paths taken by anthropologists and researchers in education when they adopt ethnography in their research. In focus, a scientific field under construction: the anthropology of $/$ and education. The text presents the alternatives under the ethnographic work of researchers interested in the relationship between these two scientific fields. It is considered that the theoretical choices enable several results because they depend on the principles and tools adopted in the scientific practice of each field. Which are such principles and tools? And what about its possibilities and limits?

Keywords: Anthropology, Education, Ethnography, Ethics, Scientific Fields.

1 A denominação Antropologia da Educação ou Antropologia e Educação não será tratada no âmbito deste texto. Este é um debate a ser feito de modo sério e consistente, devido a concepções diversas a respeito da relação entre os campos aqui considerados.

Recebido em 22 de setembro de 2019.

Avaliador A: 01 de novembro de 2019.

Avaliador B: 04 de novembro de 2019.

Aceito em 17 de dezembro de 2019. 


\section{INTRODUÇÃO}

A modernidade, o avanço tecnológico e o mundo informacional numa ordem social globalizada exigem, cada vez mais, que a educação e sua agência maior, a escola, conformem-se às imposições desse "novo" tempo. Nesse contexto, a educação se faz ferramenta fundamental, mas, com frequência tem sido pensada tão somente como escolarização. No entanto, hoje muitos antropólogos (BRANDÃO, 1981; 2002; GUSMÃO, 1997; 2015; DAUSTER, 2007; DAUSTER, TOSTA, ROCHA, 2012) assumem por princípio, que a realidade complexa, múltipla de diferentes sociedades, povos e culturas constitui diversos e diferentes processos educativos cujo centro, não se faz restrito a espaços escolarizados, mas, se realiza por meio da aprendizagem e ao longo da vida de sujeitos portadores de histórias pessoais e sociais específicas. Nesse sentido, a aprendizagem se faz processo múltiplo e diverso, sempre em movimento e sempre inacabado. Sua dinâmica atrela-se ao universo cultural dos sujeitos sociais em relação às exigências do tempo histórico que ordena a vida social em contexto.

Por outro lado, o campo científico das sociedades modernas se defronta com a questão da diversidade social e cultural de diferentes povos, grupos e culturas, tornando fundamental a questão da aprendizagem para instituir ou fortalecer um ou mais campos de conhecimento. Porém, tal processo não é tranquilo. Diferentes controvérsias colocam perguntas sobre quais dentre as ciências instituídas, por trajetórias e ferramentas teóricas próprias, postulam se fazer instituintes. Seriam elas, as ciências existentes, capazes de construir caminhos abrangentes de explicação da realidade social? Desse movimento denso de inquietações no campo científico emergem perspectivas diversas ora em complementaridade, ora em confronto, ordenando possibilidades e caminhos diversos no fazer ciência.

Para demonstrar alguns desses muitos caminhos, busca-se aqui falar a partir da antropologia entendendo esta como uma ciência da ação, cuja prática se faz mediadora das relações dessa sociedade moderna com outras sociedades, povos e culturas, sempre num contexto de tensão, de poder e sempre como parte integrante do campo político das relações entre sujeitos sociais diversos. Essa perspectiva constitui uma antropologia centrada nas relações de alteridade e de desigualdade que, como diz Dietz (2016), deixa de lado essencialismos simplistas e busca processos de interculturalidade, de troca e equidade entendidas como uma das tarefas da antropologia e, em particular, na relação com outro campo, a educação. Se existiu e existe uma trajetória da antropologia com a educação que possibilita pensar em uma antropologia da/e educação, torna-se necessário admitir que a educação também teceu e tece caminhos próprios 
para se relacionar com a antropologia. Não excludentes, tais caminhos se apresentam diversos, porém, capazes de aproximações, de aceites e soma ou de negação e rejeição no pensamento científico. Essa relação específica, se faz assim, um complexo desafio que exige saber o lugar do qual fala, tanto o educador, como o antropólogo.

Nas discussões que se seguem o lugar da fala leva em conta um consistente debate no campo da antropologia. Fato que implica ter presente as dimensões do passado e do presente da ciência antropológica em relação a educação, de modo a buscar por processos de mediação que apontem para avanços e limites dessa trajetória e tornem possível estabelecer diálogos fecundos e simétricos entre as áreas em questão.

A multiplicidade de olhares em torno do que seja educação, as trajetórias de idas e vindas na relação entre ambos os campos, exigem um pensar e refletir em contexto no tempo. Colocam em tela, também, a necessidade de refletir sobre a ciência que praticamos, suas ferramentas e princípios.

\section{ANTROPOLOGIA E EDUCAÇÃO: UM TEMA EM DISCUSSÃO}

A antropologia tem se constituído historicamente como um saber de fronteiras e, por vocação interdisciplinar estabelece debates com diversas áreas do conhecimento. Em sua interface com a educação, o diálogo não é novo e se reporta a uma longa tradição (GUSMÃO 1997; 2015; OLIVEIRA, 2015). Atualmente, antropólogos no Brasil, na América Latina, na Europa têm investido em pesquisas diversas com diferentes abordagens, de modo a intensificar o diálogo e fortalecer centros pesquisas na área da antropologia e na da educação. Contudo, o desenvolvimento mais visível desse debate se dá a partir dos anos de 1990, devido aos movimentos de reconhecimento da diversidade social e cultural brasileira na Constituição de 1988. Desde então, o diálogo entre as duas áreas de conhecimento, a antropologia e a educação, tem sido implementada por reflexões mais sistemáticas de antropólogas e antropólogos brasileiros, num campo de estudos e de atuação que se consolida por meio de pesquisas, publicações e atuações práticas em diferentes instâncias públicas e privadas.

Tal incremento tem a ver com implicações políticas, teóricas e metodológicas geradas pelo debate tenso e promissor que iniciado no passado, reverbera no presente e, nos faz perguntar sobre o futuro de um campo: o da antropologia da/e educação. Não sem preocupação, talvez, já que o novo contexto da sociedade brasileira, neste início do século XXI, pode colocar 
em risco todas as conquistas anteriores e todo o avanço do conhecimento. Daí a importância do registro que aqui se faz, para que futuros acadêmicos possam ser, quem sabe, os artífices de um novo tempo e contar uma outra história da relação entre antropologia e educação.

\section{ANTROPOLOGIA, EDUCAÇÃO E SUAS CATEGORIAS}

A antropologia tem sido convocada a se posicionar, desde sempre, acerca da multiplicidade da realidade cultural e social e, assim, se defronta com a diversidade existente. Por sua vez, a educação, vista como educação escolarizada, têm se defrontado com essa mesma realidade e enfrenta o desafio de superar perspectivas mais homogêneas de seu trajeto histórico e institucional (GUSMÃO, 1997; 2015) e, assim, criar alternativas para o processo educacional, compreendido, na maioria das vezes, como tão somente ensino (ITURRA, s.d.)².

Para a antropologia, discutir tal temática leva a que a própria noção de educação seja apreendida numa concepção mais plural e alargada de educação, não reduzida à ideia de escolarização, mas, como parte do processo educativo plural e diverso, dentro e fora do ambiente escolar. Tal desafio não é simples e nem é fácil em quaisquer dos dois campos. As muitas dificuldades estão dadas tanto pelo aparato teórico de cada um dos campos quando em relação, como também, dizem respeito às concepções que envolvem a ciência e o fazer da ciência, seja na antropologia, seja na educação. Duas questões se colocam: a diversidade do campo teórico e das práticas científicas em cada uma das áreas e, a segunda diz de mecanismos, ainda em construção, para colocar ambas as disciplinas em relação, sem distorções em um campo e outro. A relação que se busca é por complementariedade, cooperação, mas isso não se faz sem conflitos. Antes de tudo por que o processo educativo nem sempre é compreendido de igual modo pelas áreas em questão.

No caso da educação e de sua prática - a Pedagogia - é clássica a compreensão dos processos escolarizados como ação educativa, fato que difere da compreensão das mesmas no campo educacional. No primeiro caso, se trata de ação educativa ou educacional que é de ordem prática e mais prescritiva (LOVISOLO, 1984). Diagnostica, prescreve a ação de intervenção sobre uma dada situação, para solucionar ao que é tido como "problema" no ambiente escolar

2 Para Raul Iturra (s.d), a educação no sistema capitalista separa ensino da aprendizagem. A composição com hífen entre os dois termos, demonstra uma dificuldade de entender um processo e outro, já que a palavra composta sugere serem ambos os termos uma só realidade. 
e fora dele. Objetiva por meio da socialização ${ }^{3}$, interiorizar sentimentos, hábitos, valores inerentes à ordem social. O ser social é sujeito passivo das relações de ensino. Permanece na superfície do social: detecta as diferenças e as reconhece. No caso do campo educacional, trata-se de ordem mais ampla e crítica, pois busca uma visão compreensiva da realidade social, mais interpretativa, ordenada pelo campo político e pelas relações de poder. Nele se discutem o ser e o dever ser de sujeitos sociais concretos e seus múltiplos significados. Tem por paradigma a noção de conflito. Considera a dinamicidade da produção e da reprodução do mundo social a partir da noção de sociabilidade ${ }^{4}$ ainda que não negue a socialização. Tal perspectiva considera que o ser social é participante ativo do social e sujeito de conhecimento, onde quer que esteja e atue.

No primeiro caso o que está em questão são as possibilidades do ensino e não necessariamente a aprendizagem, tal como se espera no segundo caso. É evidente nas duas perspectivas, que a pesquisa em uma ou outra concepção, mesmo que olhem para o mesmo objeto e o mesmo contexto, chegarão a resultados divergentes e a ações diversas de intervenção no social. Isso expõe os limites do conhecimento no fazer da pesquisa quando não se tem claro o ponto teórico de partida e as categorias próprias desse campo. Daí a necessidade de ter claro o lugar de nossas falas como pesquisadores.

A proposta que aqui se faz, portanto, é demonstrar os caminhos seguidos por antropólogos que pesquisam a educação ${ }^{5}$ e, fundamentalmente, colocam a ciência e aqueles que a praticam a entenderem o conhecimento como questão moral e ética.

\section{ANTROPOLOGIA E EDUCAÇÃO: 0 QUE DIZEM OS ANTROPÓLOGOS}

Um pequeno panorama a respeito da antropologia e do que fazem os antropólogos preocupados com educação será tratado aqui, sob a perspectiva de que:

\footnotetext{
3 Socialização: pressupõe a intencionalidade de formação do indivíduo em termos de normas e valores vigentes na sociedade e transmitidos por meio de uma geração adulta para uma geração mais nova que assume assim, as condutas previstas na/pela sociedade

4 Sociabilidade humana: "a um território comunicante e interativo, lócus de mediação entre individualidade e sociedade, entre expressão e identidade, cuja relação é possibilitada pela cultura como esfera do social propiciadora de trocas e capacitadora de diferentes tipos de vida" (GUSMÃO, 1999, p. 52).

5 Alguns dos autores vieram de campos afins como a sociologia e a educação, porém, possuem formação e/ou atuam na interface da antropologia.
} 
[...] há muitos caminhos pelos quais a interface Antropologia da/e Educação pode ser considerada, já que este é um campo em permanente construção no Brasil, na América Latina e, mesmo no velho mundo. (ECKERT; GUSMÃO; TOSTA; DAUSTER, 2017, p.12).

O que importa é que se trata de um campo científico que articula ética, política e ciência, tal como diz Macedo (2007, p.82). Ou seja, que pensa a antropologia e seu método - a etnografia - como possibilidade de uma ciência da ação, ciência da prática ${ }^{6}$. A antropologia como ciência da ação é entendida como aquela que se preocupa com a moral e a ética na relação com os sujeitos que pesquisa. Trata-se de uma ciência de mediação que faz do antropólogo um mediador com responsabilidades teóricas e práticas. Por esta perspectiva compreende-se que o mediar “já [...] seria uma forma de agir", o que nos remete automaticamente à esfera da ética e da moral, seja nas atividades acadêmicas, de assessoramento no serviço público ou nas ONGs", como apontam Victoria, Oliven, Maciel e Oro, citando Cardoso de Oliveira na introdução da obra organizada por eles (2004, p. 15). Podemos ampliar a assertiva para outros espaços de ação e intervenção social, mas, se desde muito, a antropologia afirma ser "sempre comprometida, o que importa [perguntar] é com quem ela está comprometida" (RESTREPO, 2014, p.378), essa uma discussão permanente que não pode ser esquecida no fazer científico de qualquer campo das chamadas humanidades.

Assim, os desafios no fazer da antropologia permitem perspectivas múltiplas de construção dessa ciência e, em particular, de uma antropologia da/e educação hoje. Nessa complexa dimensão se colocam as possibilidades dessa relação de ambos os campos, sem que sejam excludentes uma da outra como por vezes se interpreta.

Para evidenciar caminhos novos e emergentes nesse debate, organizei um Dossiê em 2013, para a Revista Pro-Posições (FE/Unicamp) e um outro Dossiê em 2016 (UFPe) foi organizado por mim em parceria com os antropólogos Marion Teodósio Quadros (UFPe) e Gunther Dietz (Universidad Veracruzana, do México). As obras em tela, pretenderam expor algumas das vertentes de pesquisa antropológica trabalhadas no Brasil em nome de uma antropologia da/e educação ${ }^{7}$ e, também, da parte de alguns pesquisadores estrangeiros. Evidente que tanto os temas como as abordagens apresentadas constituem visões contemporâneas de uma ciência antropológica moderna e propositiva. No entanto, em ambos os casos se trata de amostragem

6 Antropologia da ação difere da antropologia aplicada do início do século XX, comprometida com o colonialismo e "solidária com um praticismo inaceitável" como diz Roberto Cardoso de Oliveira (2004, p. 21).

7 Tanto no Dossiê de 2013 como no de 2016, a questão do de e do $\boldsymbol{e}$ - antropologia da/e educação - não foram tratados, permanecendo a designação dada pelos autores em seus respectivos textos. 
parcial do que fazem alguns antropólogos preocupados com o campo educacional. São pesquisadores que reconhecem a heterogeneidade do social, com múltiplas experiências e assumem a teoria e a prática como elementos inseparáveis na construção do conhecimento, marcas do método antropológico diante de sujeitos diversos - da realidade indígena à realidade étnica e cultural presente na sociedade brasileira.

\section{DOSSIÊ "FORMACÃO DOCENTE PARA A DIVERSIDADE: DILEMAS, DESAFIOS E PÉRSPECTIVAS NO DIÁLOGO ANTROPOLOGIA E EDUCAÇÃO"8}

O título de uma obra importa, pois pretende-se que o mesmo seja indicador objetivo dos conteúdos tratados. Com isso, a primeira análise do título do Dossiê $2013^{9}$ aponta para dois temas centrais: a formação docente e a diversidade, seja ela social e/ou cultural. Aponta ainda para dois campos de conhecimento: a antropologia e a educação. A partir dessa consideração pergunta-se: o Dossiê 2013 tem por núcleo tais temáticas?

O Dossiê 2013 está composto por sete textos. Seis textos trazem no título a questão da formação docente em escolas brasileiras, argentinas e portuguesas. Trazem ainda a questão da formação docente entre indígenas e, com isso apontam para a diversidade social e cultural dos sujeitos. Pode-se também observar que, dois textos dentre eles se preocupam em apontar modelos educativos de formação docente para a diversidade. Com isso posto, cabe perguntar a finalidade da proposta: o conjunto de textos deste Dossiê dizem o quê a respeito da relação antropologia e educação?

Dos temas e olhares construídos há perspectivas que focam a tradição antropológica com a questão da educação num longo espectro temporal e teórico: do séc. XIX ao séc. XXI. Aqui, trata-se de um olhar historicizado para compreender o passado dessa ciência e pensar seu presente e futuro, colocando em tela a antropologia aplicada dos anos de 1930 e os caminhos de superação de seus limites. Outra perspectiva incide sobre intensos processos de imersão

8 GUSMÃO, N. M. M. Apresentação do dossiê formação docente para a diversidade: dilemas, desafios e perspectivas no diálogo entre Antropologia e Educação. Pro-Posições, v.24, n.2(71), maio/ago.2013. Campinas/UNICAMP, p. 17-123. Disponível em: https://www.scielo.br/scielo.php?script=sci_arttext \&pid=S0103-73072013000200002.

9 A apresentação do conteúdo dos dois Dossiês, a partir de agora designados como Dossiê 2013 e Dossiê 2016, não explicita o nome de cada autor dos textos comentados, apenas o faz quando de citação específica. 
etnográfica para situar a interface da antropologia com a educação a partir da antropologia social e cultural que se configurou na institucionalização dessa ciência no Brasil. Nestes casos, discute-se o papel de uma antropologia social e cultural, como fundamental na compreensão de aspectos marginais e/ou de sujeitos minorizados do mundo social. Sujeitos que reivindicam lugares próprios e autônomos no mundo social por meio da educação, tal como populações indígenas, ribeirinhas e quilombolas. Nesta perspectiva, a pesquisa, o campo, a teoria e a prática antropológica se fazem num intenso contexto de troca interdisciplinar que toma por foco a formação pessoal e coletiva de sujeitos alvo de políticas públicas que constituem "Antropólogos em Ação" e que se estrutura no Brasil a partir dos anos de 1980/90 em diante. Resulta desse movimento a formação de professores indígenas, de professores da rede pública, numa experiência partilhada com antropólogos, psicólogos, educadores, comunidades e alunos, numa clara concepção de interdisciplinaridade e parte do processo de ação mediadora entre conhecimento e ação.

Por sua vez, a experiência docente se apresenta a partir de trajetos diversos da antropologia na América Latina e no Brasil, colocando lado a lado concepções antropológicas também diversas. Nesse caso específico, recupera-se o valor analítico das próprias experiências como ferramenta para ver, compreender e interagir com outras experiências e, assim, gerar possibilidades de conhecimentos mais profundos e superar pré-noções que se expressam na prática docente.

Um dos contributos fundamentais da antropologia como antropologia da/e educação é o assumir como central a formação docente para a diversidade, os processos reflexivos e interculturais possibilitados pela etnobiografia ${ }^{10}$ como ferramenta pedagógica. De maior significância a afirmação de que a antropologia da/e educação não consiste apenas em usar a etnografia para descrever a escola e seus processos, mas, vai além. Busca compreender os processos de transformação dos sujeitos vias suas histórias de vida, pelos processos de socialização vividos e, dentro disso, situa a prática docente. Nesta concepção, se faz presente a abordagem da realidade educacional via os processos educativos na escola e fora da escola, centrados na concepção de aprendizagem permanente que pontua a condição humana em meio coletivo. O intuito é a construção de alternativas no processo educativo, que possibilitem a descoberta conjunta de meios de ação e reflexão tanto da parte do professor como do aluno e, que ambos possam assim, construir uma compreensão abrangente a respeito do mundo social.

10 Para Vieira (2013), a etnobiografia tem a história de vida como ponto de partida para a compreensão do sujeito e, implica uma análise extensiva a todas as dimensões da sua existência. São ainda, vias para compreender os processos educativos (p.117). 
Do resumo pontual e limitado do conjunto de textos emerge com clareza a objetividade da proposta do Dossiê 2013 quanto aos temas considerados e, também quanto a relação antropologia e educação. Contudo, o próprio Dossiê tem por subtítulo, um outro debate, qual seja: dilemas, desafios e perspectivas no diálogo antropologia e educação. Quais os dilemas e desafios encontrados? A partir dessa leitura, quais as perspectivas apontadas?

Os textos que cobrem o espectro temporal e teórico da tradição antropológica, apontam para o desconhecimento da antropologia e de seu modo específico de fazer ciência no campo educacional, não só entre pesquisadores da educação, como também, entre os próprios antropólogos. Mais que isso, as pesquisas que adentram o espaço escolar mostram que o que mais perguntam os professores é: o que é antropologia? O que a antropologia sabe fazer na formação de professores? (ROSISTOLATO, 2013). O texto discute a resistência por parte da escola aos discursos externos a ela. Afinal, o que a antropologia teria a dizer na formação de professores? Isso também se dá com os antropólogos que desconhecem na trajetória histórica da antropologia, a importância da educação e da "antropologia pedagógica" presente nas escolas normais entre o final do século XIX e início do século XX, como diz Oliveira (2015). Outros textos apontam para a dificuldade de compreender que, "as abordagens que sistematizam o pensamento e o fazer antropológico na educação se apresentam como não definidas por um modo único de produzir conhecimento, constituindo um campo em construção e de muitas possibilidades" (GUSMÃO, 2013a, p. 19).

Os debates em todos os textos falam da relação antropologia e educação como um espaço aberto de possibilidades e alternativas. Por esta razão, trata-se também, de entender que "o diálogo entre campos diversos constitui um campo de tensão e de "relações perigosas" (GUSMÃO, 2013a, p.19), posto que a relação entre antropologia e educação não é apenas um diálogo disciplinar senão que é, também, um campo de tensão de natureza política. Em jogo, a compreensão da luta daqueles que no mundo social sempre foram sujeitos do olhar antropológico - negros, indígenas, idosos, analfabetos, e outros -, e que hoje buscam consolidar um lugar social de direitos e de reconhecimento por meio da educação. Desafiam, portanto, a escola como instituição e a formação de professores, buscando resgatar a igualdade a partir das diferenças. Nesse sentido, os autores apontam para os diferentes sentidos da noção de cultura e a importância de repensar seu uso na educação escolarizada, já que, quase sempre é vista de forma instrumental, "sem o embasamento teórico que a sustenta e [que] isso exige colocar estudos e práticas sociais e pedagógicas em alerta” (GUSMÃO, 2013a, p. 20). A relação antropologia e educação é "pouco explorada, pouco trabalhada por antropólogos, cientistas sociais ou educadores [...] Resulta daí a imensa dificuldade no recorte a ser feito, de modo a 
demarcar tanto o desenvolvimento de uma área e outra, como as relações entre ambas" (Idem, p. 21).

Finalmente, o Dossiê 2013, diante da complexidade do debate, tanto na dimensão de atuação dos antropólogos como na prática cotidiana do professor em sala de aula propõe aos antropólogos e educadores/pesquisadores, a reflexão crítica e permanente da formação desses profissionais, de suas histórias de vida, do campo político e científico em que estão inseridos e, que a educação, em amplo sentido e não apenas escolarizada, seja reconhecida como fundamental na formação de qualquer cidadão e, também naquele que educa e pesquisa.

\section{DOSSIÊ: ANTROPOLOGIA, EDUCACÃO, ALTERIDADES E DESIGUALDADES ${ }^{11}$}

Não é possível aqui, a análise de cada texto nos moldes feito com o Dossiê 2013, mas, para uma rápida visualização elenca-se alguns dados e algumas considerações em torno das mesmas questões ali colocadas, quais sejam: A) qual a proposta contida no título? B) Os conteúdos tratados correspondem à proposta? C) O conjunto de textos do Dossiê 2016 dizem o quê a respeito da relação antropologia e educação?

\section{A) Do título}

A abrangência do título e a não existência de um subtítulo que aponte para um núcleo específico, não compromete a compreensão de que a antropologia e a educação como campos científicos estão orientadas por duas categorias - alteridades e desigualdades. Observa-se que os termos diferem em sua natureza, alcance e historicidade. Neste sentido, os dois campos de conhecimento se relacionam com diferentes perspectivas colocadas pelas categorias que também não são unas e objetivas, mas sim, relativas. Por quê é assim? Para Alves (2005) além de cada matriz teórica ter suas próprias categorias centrais, há ainda outras subordinadas, complementares que dela decorrem. Não apenas isso, deve-se compreender que:

[...] a sociedade em seu movimento impõe ao pesquisador, a produção

11 GUSMÃO, N. M. M.; QUADROS, M. T.; DIETZ, G. (Org.). Apresentação: Antropologia, Educação, Alteridades e Desigualdades. Anthropológicas. Ano 20, Volume 27(1), 2016. p. 1 - 271. Disponível em: https:// periodicos.ufpe.br/revistas/revistaanthropologicas/article/download/24033/19495. 
permanente de novas categorias à medida que se avança no conhecimento das realidades empíricas que estuda. O fato coloca como necessária a flexibilização das categorias na apreensão de uma realidade que se busca conhecer sob o risco de engessar o próprio conhecimento caso isso não ocorra $[\ldots]$ Tudo isso tem a ver com o contexto histórico da sociedade $[\ldots] \mathrm{e}$ por seus reflexos na vida acadêmica. (GUSMÃO, 2013b, p. 219)

No Dossiê 2016, as categorias se fazem amplas e diversas, tanto na definição como no conteúdo e no uso que se faz delas nas pesquisas relatadas. Se isso aponta para algo qualitativo dado que as categorias não são absolutas, também apontam para o desafio de utilizá-las como ferramentas analíticas que, mais que relativas, são relacionais, ou seja, definem-se em contexto situacional, histórico e político, que moldam as categorias científicas de cada momento e lhes atribuem legitimidade (GUSMÃO, 2013b). Esta complexidade exige reflexão constante e crítica por parte dos pesquisadores - na antropologia e na educação - para delimitarem o alcance e os desafios das abordagens que adotam em suas análises. Fato que também incide na questão ética do fazer ciência. Contudo, isso se reflete no interior dos textos?

\section{B) Dos conteúdos}

O Dossiê 2016 se organiza em dois momentos: um ensaio inicial mais teórico aponta um universo de categorias e ideias a respeito de abordagens da diversidade social e cultural; dos encontros e desencontros da antropologia da educação. O conteúdo alerta para os essencialismos simplificadores presentes no campo e propõe a busca por processos interculturais na educação como uma das tarefas da antropologia.

Um segundo momento complementar ao primeiro e em diálogos possíveis com a proposta do ensaio, compõem-se de oito artigos divididos em dois eixos, de quatro textos cada um. O subtema do primeiro eixo é: Antropologia, formação de professores, ensino; o segundo eixo define-se como: Cultura, interculturalidade, educação indígena. Na rápida caracterização percebe-se que o ensaio e os artigos do primeiro eixo pensam o campo, ou seja, a antropologia e sua relação com processos de formação e experiências de ensino. No segundo eixo, debate-se as categorias fundamentais como cultura e interculturalidade, para então pensar o alcance explicativo das mesmas em relação a antropologia e a educação indígena. Há uma clara filiação do Dossiê 2016 à proposta do ensaio inicial como núcleo central do debate dos diversos textos.

Os debates em torno de áreas - a antropologia e a educação - e de categorias analíticas - ensino, cultura e interculturalidade - expressam seu alcance explicativo a partir de realidades concretas pesquisadas por antropólogos e pesquisadores da educação. $\mathrm{O}$ fato da junção 
do campo teórico e de categorias representativas aponta para a característica fundamental da antropologia como ciência da prática que não desconhece a base teórica e explicativa das próprias categorias como instrumentos analíticos relativos e polissêmicos. Por isso mesmo, a antropologia se faz ciência reflexiva, se faz ciência da ação. Ela própria complexa e polissêmica dado que como ciência a "antropologia não é e nem nunca foi única" (SCHUCH, 2002, p. 88). Aqui reside as possibilidades de alcance não só na ciência mais geral, a própria antropologia, mas também, de seu diálogo com esse outro campo disciplinar, a educação.

\section{C) Da relação antropologia e educação}

De início a atenção se volta para algo não explicitamente considerado no Dossiê 2016 e presente no próprio título da obra, posto que traz uma questão ainda de difícil trato na antropologia e na educação. Trata-se da categoria desigualdade que muitos pesquisadores entendem mais explicativa do que a categoria diversidade, esta, muitas vezes vista apenas, como diferença. A questão da diversidade está presente na antropologia desde os primórdios em razão do estudo dos chamados “outros”, os tidos por diferentes. Contudo, pela constituição disciplinar desse campo, na análise antropológica, a diversidade se expressa com maior alcance no interior das alteridades. Este conceito nem sempre é bem compreendido nas pesquisas educacionais e, por vezes, considera-se que o mesmo esteja limitado à relação pesquisadorpesquisado, como sujeitos diferentes em relação. Isto é já uma relação de alteridade, mas a categoria de alteridade não se reduz a isso.

O reducionismo compromete o alcance explicativo da categoria e, muitas vezes, imagina-se que estar em campo, numa relação de alteridade é fazer etnografia. Nestes casos, uma categoria analítica se reduz a uma condição instrumental, localizada e restrita. Sem alcance explicativo. Reduz também, a própria etnografia como prática científica, dado que, por esta concepção, seja suposto que a análise dos dados obtidos em campo deva buscar respaldo teórico em outro campo, quase sempre, na sociologia, posto que aí as desigualdades seriam consideradas. Este equívoco revela o desconhecimento da antropologia como campo científico em que a teoria e a prática não se separam e refletem uma concepção acrítica e ultrapassada do que seja antropologia, do que sejam e para que servem suas categorias centrais. Não se adentra assim, ao movimento histórico e continuo do campo antropológico na revisão permanente de seus princípios, de suas categorias que faz dela uma ciência legitima e de largo alcance também nas sociedades modernas.

A questão das categorias será o ponto principal de cada um dos textos do Dossiê 2016, com análises de resultados de pesquisa empírica e do fazer etnográfico no campo. Uma fértil 
demonstração da relação entre teoria e prática, na explicação de outras realidades presentes na sociedade hoje. Com esse preâmbulo adentramos então ao que disseram os antropólogos do Dossiê 2016 com respeito aos seus estudos e experiências de pesquisa no âmbito da antropologia da/e educação em termos dos avanços, possibilidades e desafios do campo teórico e prático das duas áreas em interlocução.

\section{1) Do Ensaio}

O ensaio que abre o Dossiê 2016, não foi escrito com a intenção de ser um guia teórico e prático do conjunto dos textos que organizam os dois eixos da obra. Contudo, é ele que dá o tom no diálogo da antropologia com a educação como debate contemporâneo e crítico no conjunto de textos.

O ensaio propõe a análise das alteridades e desigualdades em processos de interação assimétrica, já que seu ponto de partida é a compreensão de relações de poder. Relações estas, presentes em diferentes processos educativos, não só na escola. Aponta para uma concepção alargada de educação e a demostra num gradiente temporal de desenvolvimento da antropologia como ciência - do Séc. XIX ao início do Séc. XX -, momento que a antropologia estuda empiricamente os "processos de socialização", de transmissão entre culturas e, por esta razão, quase sempre se fez uma ciência "imediatista" de intervenção pedagógica geradora de encontros e desencontros que, ainda hoje são lembrados em meio a críticas a uma possível antropologia da educação. O que se destaca é que o Ensaio permite compreender o passado da antropologia e aponta para a dimensão do debate atual. Situa a ciência antropológica e confirma que "Os tempos são outros e a forma de fazer antropologia mudou" (MACEDO, 2007, p.84) ${ }^{12}$. Já não é possível negar a mudança e o avanço desse campo nas últimas décadas do Séc. XX e este início do Séc. XXI, tal como aponta o ensaio. O Séc. XX e o presente século tem como proposta da área antropológica o "estudo etnográfico das diversidades, das alteridades e desigualdades contemporâneas, no âmbito educativo e particularmente na escola" como $\operatorname{diz} \operatorname{Dietz}(2016$, p. 13)

O novo campo antropológico-pedagógico segundo o autor, traz consigo a confluência entre a antropologia e a pedagogia e instaura um campo interdisciplinar que tem uma nova categoria de estudo e análise, a educação intercultural. Trata-se de um avanço significativo, mas que também trouxe consigo uma

12 A referência diz respeito a antropologia dos anos de 1920/30 de cariz cultural e conservador. (GUSMÃO, 2015) 
[...] interpretação predominantemente auxiliar e instrumental do conhecimento antropológico [o autor refere-se a pesquisas no campo da educação] há criado um reducionismo conceitual-terminológico [da antropologia como ciência]" que impacta negativamente a estratégia de interculturalizar a esfera educativa (DIETZ, 2016, p.13).

Com isso, na educação predominam estudos de um multiculturalismo diferencial que reafirma o discurso pedagógico culturalista (do início do Séc. XX). Deve-se, portanto, principalmente no caso dos contextos coloniais como os da América Latina e suas relações de poder, superar este reducionismo, e retomar a compreensão e o alcance da interculturalidade e da alteridade como relações conflitivas e dialógicas.

A interculturalidade e a alteridade serão então, as categorias centrais que se apresentam em todos os textos decorrentes de pesquisa etnográfica que conformam os dois eixos do Dossiê 2016.

\section{2) Dos demais textos}

Alguns pontos do conjunto dos textos do Dossiê 2016 evidenciam os avanços e limites em estudos atuais do campo da antropologia da/e educação. As transformações da antropologia como ciência que tem a própria mudança de seus caminhos como fundamental para seu desenvolvimento é consenso nos textos apresentados. A dinamicidade e a flexibilidade do campo antropológico são vistas como propriedades qualitativas de uma ciência moderna e atual. Nos diferentes textos as principais categorias de análise que emergem são as seguintes: alteridade, cultura, reflexividade, autoridade, sociabilidade, identidade, gênero, educação, diversidade, subjetividade, relações de poder. Todas elas referidas a contextos concretos e situados que imprimem ao olhar do pesquisador diferentes formas de se estar na escola - do ensino superior à educação escolar indígena. Dizem ainda da formação de professores indígenas ou não. Por sua vez, as categorias, para além de apontarem a natureza da prática de pesquisa antropológica, dizem de seu alcance explicativo neste ou naquele contexto. Assim, o alcance analítico e teórico encontra sua substância, seu conteúdo no universo empírico, concreto e histórico de cada segmento, povo ou nação em estudo pela antropologia da/e educação.

Aponta-se também para alguns limites ou desafios a serem melhor estudados e compreendidos. A antropologia da/e educação, por mais que seja consenso que está se desenvolvendo, ainda se encontra subsumida a um "lugar periférico" dentro da própria antropologia. Ora dilui-se em outras modalidades tais como antropologia urbana, etnologia; ora aparece como decorrência de pesquisas cujo interesse principal não é a educação, mas ela se impõe no 
campo como complemento e não como objeto central. A única exceção se apresenta nos estudos de educação indígena e que, no Dossiê 2016, se faz presente em dois textos do segundo eixo.

Outra questão bastante frequente é que, embora hoje, seja crescente o número de programas de pós-graduação em antropologia, serão as instituições periféricas e não de grandes centros que buscam pelo campo disciplinar da antropologia da educação. Por outro lado, os programas de educação buscam essa interface, porém, muitas vezes o fazem vendo na antropologia um campo auxiliar, mais instrumental que analítico. Uma ciência menor.

Também nesses programas, a dificuldade muitas vezes é a de ter claro que aí não se formam antropólogos. Fato que nos leva a questionar o campo de formação e atuação dos antropólogos, já que diversas pesquisas têm demonstrado que nem sempre, nesses programas ou mesmo nos programas de graduação em pedagogia e de formação de professores, quem ministra antropologia não é, necessariamente, antropólogo por formação. Também as dificuldades de estudo at home, daqueles que nos são próximos, esbarram em empecilhos que vão desde a reflexividade necessária do campo disciplinar até aos chamados comitês de ética das instituições, posto que os modelos operacionais desses comitês não contemplam as chamadas humanidades. Aqui, a questão da ética se coloca como debate urgente e necessário para antropólogos e pesquisadores em educação, na busca por uma revisão crítica e consistente do que foi feito e do que se faz hoje na interface dos dois campos de conhecimento.

\section{FAZER CIENTÍFICO E ÉTICA: DESAFIO CONTEMPORÂNEO}

A existência de intercorrências ${ }^{13}$ na prática científica, num campo e noutro, revelam questões ainda não de todo explicitadas ou resolvidas e, não apenas na questão das categorias e ferramentas. Nesse universo de limites e dificuldades aqui apenas esboçado, importa compreender o debate ainda incipiente presente nas relações entre disciplinas e que dizem respeito ao campo da ética. Porquê disso?

Como diz Gustavo Lins Ribeiro (2004), “a ética implica a busca, por parte de uma coletividade, de princípios aceitáveis de comportamento e ação" (p. 9) que envolvem as populações

13 Intercorrências no sentido de acontecimentos que implicam a flexibilização da postura de investigação a partir de problemas emergentes e nem sempre previstos no fazer de campo, na coleta de dados e na sua análise. 
que estudamos e, aqui se centra em grande parte o debate que temos hoje na antropologia e em outros campos. O autor vai além, quando aponta para a questão da ética, presente também, na relação das fronteiras da antropologia com outras disciplinas. Neste caso particular, segundo Ribeiro, o debate já avançou com relação à ciência da saúde e às ciências jurídicas, mas, podemos dizer que não é o caso quando se fala na relação entre antropologia e educação. A relação entre ambas tem gerado desacordos, desencontros e críticas em ambos os campos, ainda que possam vir a serem superados.

Um rápido cenário dessa polêmica pode se evidenciar nos debates em torno da legislação educacional, da escola sem partido, do currículo único etc. no caso da educação e que diz respeito tanto a educadores como a antropólogos, mas que nem sempre concordam que sejam questões com perspectivas ou questões em comum. Alguns antropólogos (GUSMÃO, 1997; 2013b; DAUSTER, TOSTA, ROCHA, 2012), demonstram criticamente a apropriação de práticas antropológicas de pesquisa sem a necessária base epistemológica correspondente em pesquisas educacionais. Por sua vez, diante dessa questão alguns pesquisadores na educação negam a antropologia alegando que a mesma se pensa como superior e que pretende a submissão da educação como ciência menor ou mesmo, não ciência. Outros compreendem a ciência antropológica como "culturalista" e como tal, limitada para explicar a complexidade do presente, já que tem como ferramenta principal, o conceito de cultura e este seria apolítico, sem alcance numa sociedade de classes (GUSMÃO, 2015). Perde-se aí a compreensão da cultura como processo decorrente das relações entre os homens, portanto um campo político por excelência como diz Kuper (2002), para vê-la de modo absoluto e petrificado, apenas como produto das relações humanas.

O rápido e ligeiro retrato das relações entre a antropologia e a educação assim traçado diz dos desafios e limites da relação entre disciplinas de modo a construir caminhos de "enjaulamento" - cada campo, cada campo - mas que, via um debate mais profundo das relações entre antropologia e educação como campos científicos, podem construir muitas possibilidades de troca e compartilhamento interdisciplinar com ganhos significativos para os dois campos. Cabe alertar para o fato de que esse debate ainda está por se fazer de modo consistente e responsável pelos profissionais dos dois campos. O cenário descrito é dependente de muito esforço e abertura profissional séria e comprometida. É preciso refletir o que fazem os pesquisadores de um campo e outro na elaboração de suas pesquisas e no como destinam suas análises em termos de políticas de intervenção social. Aqui, se destaca a questão da ética.

A ética não está plenamente posta no debate desses dois significativos campos disciplinares quando em relação - a antropologia e a educação - mas, é um desafio dentre os investi- 
mentos a serem feitos. As razões são muitas, já que no caso brasileiro o campo da antropologia da/e educação é, ainda, uma dimensão em construção (GUSMÃO, 2013a, 2015). Não há espaço para tal debate neste texto, mas, pode-se dizer que, dentre as muitas dificuldades de um campo em construção, está em se assumir que a ética é parte do campo político e, com tal, sujeito a mudanças como diz Gustavo Lins Ribeiro (2004). Isso demanda tornar claro o lugar da fala tanto do antropólogo como do pesquisador em educação, não apenas pelo lugar teórico que ocupa, mas também, como sujeito social e cidadão de realidades datadas e historicamente instituídas.

Com esse entendimento, Ribeiro (2004, p. 11) torna evidente que o campo político e a ética que se adota no fazer da ciência na antropologia ou na educação não torna imunes ou isentos "os atores profissionais e sociopolíticos vinculados a esses campos". O fato nem sempre é fácil de ser reconhecido e este é o desafio da atualidade neste debate. O registro desse alerta a futuros pesquisadores dos dois campos de conhecimento tem por proposta que, pesquisadores que desenvolvem e acumulam estudos neste saber de fronteira, possam construir espaços acadêmicos de discussão conjunta para, então, contribuir com os mais diversos diálogos. Almeja-se com isso, construir um cenário possível da pesquisa educacional a partir, tanto da perspectiva da antropologia, como dos pesquisadores em educação que fazem a leitura da antropologia no seu campo de pesquisa.

\section{PARA CONCLUIR}

O momento que atravessamos é o de um ponto de inflexão de uma perspectiva ainda em constituição - uma antropologia da/e educação. $O$ fato exige que novos rumos sejam traçados, posto que se trata de um momento propício ao debate crítico e ao desenvolvimento de um pensamento analítico e comprometido. Discutir, portanto, a construção e consolidação de uma antropologia da/e educação no país, suas possibilidades e seus impasses, torna-se um desafio permanente no campo da pesquisa e da docência, seja na formação do cientista social, seja na formação de futuros educadores no campo da educação.

O fato de a antropologia da/e educação estar em construção torna necessário pensar criticamente o fazer científico, de modo a ressaltar que este não pode ser apenas e eminentemente teórico, mas também não pode ter por foco a prática acima de qualquer reflexão crítica assentada num corpus teórico consistente, mesmo que seja para negá-lo. O engajamento do antropólogo e da antropologia por ele praticada, ou ainda de qualquer outro cientista e seu 
campo, exige comparar diferentes posições, situá-las, já que, importa a concepção de ciência que adotamos na explicação desta ou daquela realidade.

Em nosso país, apesar da raridade dos estudos antropológicos sobre educação, encontra-se em emergência e construção uma antropologia da educação não atrelada apenas à questão indígena, mas ativa e atuante, também em outros contextos, igualmente objeto de reflexão/atuação de outras ciências humanas, como revelam os Dossiês aqui considerados. O aparato teórico e prático da antropologia, por sua história, permite resgatar diferentes dimensões dos processos educativos dentro e fora da escola a partir do campo educacional, de modo crítico e competente. A perspectiva que envolve o campo tensional de formação dos sujeitos, de pessoas e mesmo, da nação, entende essa dimensão social como inerente ao campo histórico e político das relações entre os homens. Condição necessária para pensar a cultura como processo e campo político por excelência, tal como se buscou demonstrar com a análise do Dossiê 2013 e do Dossiê 2016.

As possibilidades de uma antropologia da educação moderna e critica, no caso brasileiro, estão, portanto, postas no cenário acadêmico e científico, como afirma Gusmão (2013a; 2015). Cabe a nós compreender os muitos caminhos de um saber de fronteira e, assim empreender diferentes trajetórias etnográficas para dar corpo e alma a uma antropologia da/e educação que tenha em conta o ofício etnográfico na dimensão de um campo científico e ético competente para não cair em idealismos relativistas, vazios e ideologicamente comprometedores. Vale, portanto, na condição de profissionais desses dois campos - a antropologia e a educação - ficar alerta aos compromissos teóricos e ideológicos que assumimos quando adotamos uma ou outra postura no fazer da pesquisa.

Com isso voltamos ao campo da ética, da relação entre campos e ao desafio de ter que reconhecer criticamente o lugar de nossas falas como profissionais e sujeitos sociopolíticos que somos, já que, nós e o conhecimento que produzimos, não se fazem imunes ao campo político a nossa volta e às mudanças que enseja.

Também temos por obrigação responder a que e a quem serve o que produzimos com nossas pesquisas. Nesse contexto, o campo político e ético de uma ciência e de sua relação com outras ciências é, sem dúvida um desafio marcado por tensões e conflito, mas também, por liberdade e princípios, que no dizer de Cardoso de Oliveira (1998) orientam o fazer científico em termos democrático e profundamente moral. 


\section{REFERÊNCIAS}

1. ALVES, Gilberto Luiz. O trabalho didático na escola moderna. Formas Históricas. Campinas, SP: Autores Associados, 2005.

2. BRANDÃO, Carlos R. O que é educação. São Paulo: Editora Brasiliense, 1981.

3. BRANDÃO, Carlos Rodrigues. A educação como cultura. Campinas, SP: Editora Mercado das Letras, 2002.

4. CARDOSO DE OLIVEIRA, Roberto. Sobre o diálogo intolerante. In: OLIVEIRA, Roberto Cardoso de. O trabalho do antropólogo. Brasília: Paralelo 15; São Paulo: UNESP, 1998. p. 189-197.

5. CARDOSO DE OLIVEIRA, Roberto. O mal estar da ética na antropologia prática In: VÍCTORA, Ceres; OLIVEN, Ruben George; MACIEL, Maria Eunice; ORO, Ari Pedro (Org.). Antropologia e Ética. O debate atual no Brasil. Niterói, EdUFF, 2004, p. 21-32.

6. DAUSTER, Tania (Org.). Antropologia e Educação. Um saber de fronteira. Rio de Janeiro: Editora Forma \& Ação, 2007.

7. DAUSTER, T.; TOSTA, S. P.; ROCHA, G. (Org.) Etnografia e educação: culturas escolares, formação e sociabilidades infantis e juvenis. Rio de Janeiro: Lamparina, 2012 .

8. DIETZ, Gunther. Antropología, Educación, Alteridades y Desigualdades: un ensayo introductorio. Anthropológicas. Ano 20, v. 27(1), p. 1-10. 2016. Disponível em: https://periodicos.ufpe.br/revistas/revistaanthropologicas/issue/archive. Acesso em: 08 fev. 2019.

9. ECKERT, Cornelia; GUSMÃO, Neusa Maria Mendes; TOSTA, Sandra Pereira; DAUSTER, Tania. Apresentação. Horizontes Antropológicos. v. 49, p. 9-8. set./dez. 2017. Disponível em: https://journals.openedition.org/horizontes/1711. Acesso em: 08 fev. 2019.

10. GUSMÃO, Neusa Maria Mendes. Antropologia e Educação: origens de um diálogo. Cadernos CEDES. v. 18, n. 43, p. 8-25. CEDES/Campinas: dez. 1997. Disponível em: https:/www.scielo.br/scielo.php?pid=S0101-32621997000200002\&script=sci abstract\&tlng=pt. Acesso em: 09 fev. 2019.

11. GUSMÃO, Neusa Maria Mendes. Linguagem, cultura e alteridade: imagens do outro. Edição Especial. Cadernos de Pesquisa. n. 107, p. 41-78. São Paulo: Fundação Carlos Chagas; Campinas: Editores Associados, 1999. Disponível em: https://www.scielo.br/ scielo.php?pid=S0100-15741999000200002\&script $=$ sci_abstract\&tlng=pt. Acesso em: 08 fev. 2019. 
12. GUSMÃO, Neusa Maria Mendes. Apresentação do dossiê formação docente para a diversidade: dilemas, desafios e perspectivas no diálogo entre Antropologia e Educação. Pro-Posições, v.24, n.2(71), maio/ago.2013. Campinas/UNICAMP. p.17 - 123. Disponível em: https://www.scielo.br/scielo.php?script=sci_ arttext\&pid=S0103-73072013000200002. Acesso em: 08 fev. 2019.

13. GUSMÃO, Neusa Maria Mendes. Comunidades Rurais Negras ou Quilombolas? Um debate em torno de categorias e experiências. In: GODÓI, E. P.; MENEZES, M. (Org.) Uma terra para se viver: assentados, colonos e quilombolas. São Paulo: Annablube, 2013b. p. 215-235.

14. GUSMÃO, Neusa Maria Mendes. Antropologia e Educação: um campo e muitos caminhos. Linhas Críticas, Brasília, DF, v.21, n.44, p. 19-37. jan./abr. 2015. Disponível em: http://periodicos.unb.br/index.php/linhascriticas. Acesso em: 12 fev. 2019.

15. GUSMÃO, Neusa Maria Mendes; QUADROS, Maria Teodósio de; DIETZ, Gunther. Apresentação: Antropologia, Educação, Alteridades e Desigualdades. Anthropológicas. Ano 20, Volume 27(1), 2016. p. 1 - 271. Disponível em: https://periodicos.ufpe.br/ revistas/revistaanthropologicas/article/download/24033/19495. Acesso em: 12 fev. 2019.

16. ITURRA, Raúl. O processo educativo: ensino ou aprendizagem? Educação, Sociedade \& Cultura, n. 1, p.20-50. [s.d.].

17. KUPER, Adam. Cultura. A visão dos antropólogos. EDUSC. Bauru, SP: 2002.

18. LIMA, Rita de Cássia Pereira. Sociologia do desvio e interacionismo. Tempo Social - Revista de Sociologia da USP. v.13, n. 1, p. 185-201. 2001. Disponível em: https:// www.scielo.br/pdf/ts/v13n1/v13n1a12.pdf. Acesso em: 08 fev. 2019.

19. LOVISOLO, Hugo. Antropologia e educação na sociedade complexa. Revista Brasileira de Estudos Pedagógicos. n. 65, p. 56-69. jan./abr. 1984.

20. MACEDO, Juliana Lopes de. Direitos Sexuais e Reprodutivos sob a Ótica da Antropologia. In: FLEISHER, Soraya; SCHUCH, Patrice; FONSECA, Claudia. (Org.). Antropólogos em Ação: Experimentos de Pesquisa em Direitos Humanos. Porto Alegre: Editora da UFRGS, 2007. p. 77-90.

21. OLIVEIRA, Amurabi. Apresentação. Linhas Críticas. v.21, n.44, p. 11-17. Brasília, DF: jan./abr. 2015. Disponível em: http://periodicos.unb.br/index.php/linhascriticas. Acesso em: 12 fev. 2019.

22. RESTREPO, Eduardo. Desdisciplinar a antropologia: diálogo com Eduardo Restrepo. Horizonte Antropológico. v. 20, n. 41, p. 359-379. Porto Alegre: jan./jun. 2014. Disponível em: https://lume.ufrgs.br/handle/10183/135078. Acesso em: 26 fev. 2019.

23. RIBEIRO, Gustavo Lins. Prefácio. In: VICTORA, Ceres; OLIVEN, Ruben George; MACIEL, Maria Eunice; ORO, Pedro (Org.). Antropologia e Ética. O debate atual no 
Brasil. Niterói: EdUFF, 2004. p. 9-12.

24. ROCHA, Gilmar; TOSTA, Sandra de Fátima Pereira. Antropologia e educação. Belo Horizonte: Autêntica Editora, 2009.

25. ROSISTOLATO, Rodrigo. "Você sabe como é, eles não estão acostumados com antropólogos!": uma análise etnográfica da formação de professores. Pro-Posições. v. 24, n. 2 (71), p. 41-54. mai./ago. 2013. Disponível em: https://periodicos.sbu.unicamp. br/ojs/index.php/proposic/issue/view/884. Acesso em: 08 fev. 2019.

26. SCHUCH, P. O "estrangeiro" em "campo": atritos e deslocamentos no trabalho antropológico. Antropolítica: Revista Contemporânea de Antropologia. Niterói, n. 12/13, p.73-91. 2002.

27. VIEIRA, Ricardo. Etnobiografias e descoberta de si: uma proposta da Antropologia da Educação para a formação de professores para a diversidade cultural. Pro-Posições. v.24, n.2(71), p.17-25. mai./ago. Campinas/UNICAMP: 2013a. Disponível em: https://www. scielo.br/scielo.php?pid=S0103-73072013000200009\&script $=$ sci_abstract\&tlng=pt. Acesso em: 12 fev. 2019.

28. VÍCTORA, Ceres; OLIVEN, Ruben George; MACIEL, Maria Eunice; ORO, Ari Pedro (Org.). Antropologia e Ética. O debate atual no Brasil. Niterói: EdUFF, 2004.

Neusa Maria Mendes de Gusmão

Doutora em Ciência Social (Antropologia Social) pela Universidade de São Paulo (1990). Pós-doutora pelo Instituto de Ciências Sociais da Universidade de Lisboa em 1998 e 2002. Professora titular aposentada da Universidade Estadual de Campinas. ID ORCID: http://orcid. org/0000-0002-5627-1286. E-mail: neusagusmao@uol.com.br. 